\title{
IDENTIFIKASI MODEL ADAPTASI BENCANA DI KAWASAN SENG HIE DAN DESA SUNGAI KAKAP
}

\section{Bontor Jumaylinda Br. Gultom}

Jurusan Arsitektur, Fakultas Teknik, Universitas Tanjungpura, Pontianak bontor_jl@teknik.untan.ac.id

\section{Dian Rahayu Jati}

Jurusan Teknik Lingkungan, Fakultas Teknik, Universitas Tanjungpura, Pontianak dianjati@teknik.untan.ac.id

\section{Andi}

Program Studi S-1 Arsitektur, Fakultas Teknik, Universitas Tanjungpura, Pontianak andi.zhang2@gmail.com

\begin{abstract}
Abstrak
Kenyataan adanya bencana banjir akibat air pasang tinggi tahunan di kawasan waterfront tidak membuat kawasan tersebut menjadi tidak layak huni. Kawasan Seng Hie dan Desa Sungai Kakap merupakan kawasan waterfront yang menjadi permukiman yang bertahan dan beradaptasi dari dulu hingga sekarang. Bangunan di dua kawasan ini beradaptasi dan mengalami renovasi. Penelitian ini bertujuan untuk mengidentifikasi bentuk model adaptasi dari segi elemen bangunan dan perilaku. Dalam penelitiani ini, elemen bangunan dibatasi hanya pada elemen selubung bangunan saja yang terdiri dari lantai, dinding, dan atap. Metode dalam penelitian ini adalah metode kualitatif. Teknik pengumpulan data dalam penelitian ini adalah dengan teknik triangulasi (observasi, wawancara dan studi dokumentasi). Objek penelitian ini adalah 15 rumah di Kawasan Seng Hie dan 25 rumah di Desa Sungai Kakap yang ditentukan dalam segmen-segmen kawasan. Objek ini dipilih secara random sebagai sampel dari tiap segmen kawasan. Hasil dari penelitian ini adalah ditemukan 5 jenis model adaptasi bencana yang dimana masing-masing model memiliki kombinasi adaptasi bangunan dan adaptasi perilaku yang berbeda-beda.
\end{abstract}

Kata-kata Kunci: Air Pasang, Adaptasi Bangunan, Adaptasi Perilaku, Waterfront, Elemen Bangunan

\section{IDENTIFICATION OF DISASTER ADAPTATION MODELS IN SENG HIE AND SUNGAI KAKAP}

\begin{abstract}
The fact that there was a flood due to annual high tides in the waterfront area did not make the area uninhabitable. Seng Hie and Sungai Kakap Village are waterfront areas that have become settlements which survived and adapted from the past until now. Buildings in these two areas are changing and undergoing renovation. This study aims to identify forms of adaptation models in terms of building elements and behavior. In this study, the building elements are limited to the building envelope consisting of floors, walls, and roofs. The method in this study is a qualitative method. Data collection techniques in this research are triangulation techniques (observation,
\end{abstract}


interviews and documentation study). The objects of this study were 15 houses in the Seng Hie area and 25 houses in Sungai Kakap Village, which were determined in regional segments. This object is chosen randomly as a sample of each regional segment. The results of this study are found 5 types of disaster adaptation models in which each model has a different combination of building adaptation and behavior adaptation.

Keywords: High Tide, Building Adaptation, Behavior Adaptation, Waterfront, Building Elements

\section{Pendahuluan}

Berdasarkan bencana yang pernah terjadi di Kalimantan Barat, Wardhana (2010) mengatakan bencana yang sering terjadi di Kalimantan Barat dapat dikategorikan sebagai bencana berbasis air (hydrometeorology hazards). Bencana berbasis air adalah bencana yang diakibatkan oleh kondisi air yaitu banjir dan bencana yang berkaitan dengannya seperti pasang air laut. suhu ekstrem dan kebakaran hutan (Wardhana, 2010). Bencana hidrometeorologi yang paling berdampak pada kehidupan penduduk di sekitar sungai dan laut (waterfront) adalah pasang air laut. Bencana ini merupakan bencana tahunan yang selalu terjadi di pengujung tahun. Meskipun demikian, wilayah di sekitar sungai dan laut masih menjadi tempat incaran sebagai permukiman.

Kehadiran bencana tidak membuat wilayah ini menjadi tidak layak ditinggal. Sebaliknya masyarakat terus beradaptasi mengubah lingkungan dan perilakunya agar sesuai dengan kondisi yang ada (bencana). Adaptasi yang dilakukan terus-terusan ini seolah menjadi karakter kawasan. Adaptasi bangunan yang dilakukan disesuaikan dengan naik-turun pasang air. Adaptasi perilaku dilakukan masyarakat dengan mengubah tindakan dan kebiasaan mereka. Bentuk bangunan yang ada di daerah waterfront tersebut menjadi bukti adaptasi bangunan dan perilaku yang dilakukan terus-terusan.

Kawasan Seng Hie merupakan kawasan waterfront yang berbatasan dengan Sungai Kapuas. Menurut Misavan dan Gultom (2014), sejak masa 1980-an, kawasan Seng Hie sudah menjadi pasar yang sangat ramai dan mewah. Kawasan waterfront lainnya adalah Desa Sungai Kakap yang berbatasan dengan sungai dan muara laut. Kedua tempat ini selalu dilanda banjir akibat air pasang tinggi setiap penghujung tahun. Meskipun begitu, dua kawasan ini masih bertahan sampai sekarang dan bahkan berkembang pesat.

Berdasarkan fenomena-fenomena di atas, tim peneliti melihat sebuah keunikan dari tindakan adaptasi yang dilakukan masyarakat kawasan waterfront. Oleh sebab itu, menarik untuk diteliti tentang tindakan adaptasi bangunan yang dilakukan masyarakat kawasan waterfront dan dilihat dari perubahan elemen bangunannya serta dari adaptasi perilaku masyarakatnya. Tujuan penelitian ini adalah untuk menemukan model adaptasi bencana dari tindakan adaptasi bangunan dan adaptasi perilaku yang dilakukan masyarakat kawasan waterfront Seng Hie dan Desa Sungai Kakap.

\section{Air Pasang}

Pusat Vulkanologi dan Mitigasi Bencana Geologi (2007) dalam Hermon (2018) mendefinisikan bencana hidrometeorologi sebagai peristiwa atau rangkaian peristiwa yang mengancam dan mengganggu kehidupan dan penghidupan masyarakat yang disebabkan, baik oleh faktor alam dan faktor manusia yang berkaitan dengan air sehingga mengakibatkan timbulnya korban jiwa manusia, kerusakan lingkungan, kerugian harta benda, dan dampak psikologis. Salah satu contoh bencana hidrometeorologi adalah air pasang laut. Air pasang tinggi merupakan air pasang yang tingginya lebih dari pada umumnya, fenomena tahunan ini dialami hampir semua wilayah pesisir di Indonesia dan pesisir Kalimantan Barat adalah salah satunya. Fenomena ini juga dialami di luar negeri dan disebut dengan istilah king tides. Air pasang tinggi adalah gelombang pasang tertinggi yang terjadi setiap tahun di daerah pesisir, dan disebabkan oleh orbit dan kesejajaran dari 
Bumi, Bulan dan Matahari (Universitas Broward Country, 2018). Air pasang tinggi dapat terjadi dengan disertai badai ataupun saat cuaca cerah.

Karakteristik air pasang tinggi di wilayah pesisir Indonesia dipengaruhi oleh angin musim ( $E l$ Nino La Nina dan Indian Ocean Dipole Mode). Ada 3 jenis gelombang berdasarkan penyebabnya yakni gelombang akibat angin, gelombang akibat tsunami, dan gelombang akibat gravitasi bulan dan matahari. Dalam penelitian Kurniawan dkk. (2012) terdapat data ketinggian gelombang tahunan. Data penelitian tersebut menyatakan bahwa untuk area waterfront Kalimantan Barat yang berhubungan langsung ataupun berhubungan cukup dekat dengan perairan Laut China Selatan dan Selat Karimata akan mengalami air pasang tinggi pada bulan November sampai bulan Maret. Air pasang tertinggi terjadi di bulan Desember dan bulan Januari. Area waterfront tersebut antara lain adalah Desa Sungai Kakap dan Kawasan Seng Hie.

Air pasang tinggi menyebabkan banjir yang berdampak negatif bagi masyarakat. EPA (Environment Protection Agency) (2011) mencatat dampak dari air pasang tinggi terdiri dari naiknya resiko banjir karena kenaikan muka air laut, dan resiko kerusakan infrastruktur, rumah, dan habituasi yang sedang dipulihkan. Adapun dampak sosial-ekonomi yang dirasakan masyarakat antara lain gangguan terhadap fungsi kawasan pesisir dan kota pantai, gangguan terhadap fungsi prasarana dan sarana seperti jaringan jalan, pelabuhan dan bandara, gangguan terhadap permukiman penduduk, pengurangan produktivitas lahan pertanian, peningkatan resiko wabah penyakit, dan sebagainya (Cahyadi dkk., 2017).

\section{Adaptasi}

Adaptasi menurut KBBI (Depdiknas, 2008) adalah penyesuaian terhadap lingkungan, pekerjaan, dan pelajaran. Dalam keterkaitannya dengan arsitektur, adaptasi bangunan menekankan perubahan desain fisik bangunan terhadap lingkungan. Arge (2005) dalam Carmichael dan Taheriattar (2018) membagi adaptasi bangunan dalam 3 konsep. Konsep-konsep tersebut adalah generality, flexibility, dan elasticity. Generality adalah konsep adaptasi bangunan dimana bangunan mampu beradaptasi tanpa harus melakukan perubahan. Flexibility adalah konsep adaptasi bangunan dimana bangunan dapat beradaptasi melalui perubahan skala kecil. Elasticity adalah konsep adaptasi bangunan dimana bangunan dapat beradaptasi secara fleksibel dan dapat diubah dimensinya sesuai kondisi lingkungan.

Dalam keterkaitannya dengan lingkungan, adaptasi perilaku menekankan perubahan aktivitas manusia terhadap lingkungan. Berry (1980) dalam Yusuf dkk (2018) membagi adaptasi perilaku dalam 3 tipe. Tipe-tipe tersebut adalah adaptation by reaction, adaptation by adjustment, dan adaptation by withdrawal. Adaptation by reaction atau adaptasi dengan reaksi adalah tipe adaptasi perilaku dimana manusia menyesuaikan aktivitasnya sesuai dengan lingkungan yang ada. Adaptation by adjustment atau adaptasi dengan perubahan adalah tipe adaptasi perilaku dimana manusia mengubah lingkungan sesuai dengan aktivitas dan kebutuhan mereka. Adaptation by withdrawal adalah tipe adaptasi perilaku dimana manusia meninggalkan lingkungannya dan mencari lingkungan yang baru untuk menunjang aktivitas mereka. Dalam proses beradaptasi, adaptasi-adaptasi perilaku ini dilakukan secara berkesinambungan dengan adaptasi bangunan.

\section{Waterfront}

Sumber air memainkan peran penting di sebagian besar dunia sepanjang sejarah dalam membangun dan pembentukan pemukiman (Timur, 2013). Waterfront secara harfiah dapat diartikan sebagai tepi air (water edges) atau badan air (water body) (Gultom, 2016). Waterfront merupakan bagian dari kota yang berbatasan dengan air (Moretti, 2008). Area ini berupa dermaga tempat kapal berlabuh. Area ini penuh dengan potensi karena terdapat fenomena interaktif berupa aktivitas darat dan air (Kostopoulou, 2013).). Potensi air baik berupa sungai, danau, laut dan sebagainya 
membentuk suatu batas peralihan antar daerah perairan dengan daratan secara geografis membentuk area ini (Breen dan Rigby, 1994).

\section{Elemen Bangunan}

Ching dan Adams (2008) membagi elemen bangunan ke dalam beberapa sistem dan subsistem. Sistem-sistem tersebut adalah sistem struktural, sistem selubung, dan sistem mekanikal. Sistem selubung adalah bagian selimut bangunan yang terdiri dari atap, dinding eksterior, jendela, dan pintu, serta lantai.

Atap dan dinding merupakan bagian yang membungkus bangunan, melindungi dari cuaca buruk, dan mengkontrol hawa ruangan (Ching, 2013). Pada rumah dengan lantai gantung (tidak langsung), lantai juga dapat menjadi bagian yang membatasi bangunan dari tanah atau air di bawah rumah. Pintu menjadi elemen akses fisik. Jendela menjadi elemen yang menyediakan akses cahaya, udara, dan pemandangan.

\section{Metode}

Metode yang digunakan dalam penelitian ini adalah metode kualitatif. Penelitian ini dilakukan menggunakan pola pikir deduktif, dengan berpikir berlandaskan pandangan umum ke khusus. Pola pikir ini melihat pandangan umum bahwa daerah yang berhubungan langsung dengan air pasti lebih rentan terhadap permasalahan bencana air berupa air pasang tinggi (kenaikan permukaan air sungai atau laut). Pandangan tersebut melahirkan tindakan adaptasi, terjadi dan dilaksanakan secara bersamaan di berbagai lokasi waterfront. Penelitian ini mencari kesamaan kondisi khusus yang terjadi di Kalimantan barat yang dapat mewakili karakter waterfront.

Lokasi penelitian ini berada di 2 kawasan waterfront yang sering dilanda bencana air pasang tinggi. Kawasan pertama adalah kawasan Seng Hie di Jalan Sultan Muhammad, Kota Pontianak. Dalam observasi ini, objek dibagi menjadi 4 segmen. Sebanyak 15 rumah yang terpilih jadi objek dari kawasan Seng Hie (Lihat Gambar 1). Kawasan kedua adalah kawasan Desa Sungai Kakap. Dalam observasi ini, objek dibagi menjadi 3 segmen. Sebanyak 25 rumah yang terpilih jadi objek dari kawasan ini (Lihat Gambar 2). Di Desa Sungai Kakap, objek yang dipilih sebagai sampel lebih banyak karena luas area segment lebih besar dan jumlah rumah dalam segmen lebih banyak dibanding dengan di Kawasan Seng Hie. 


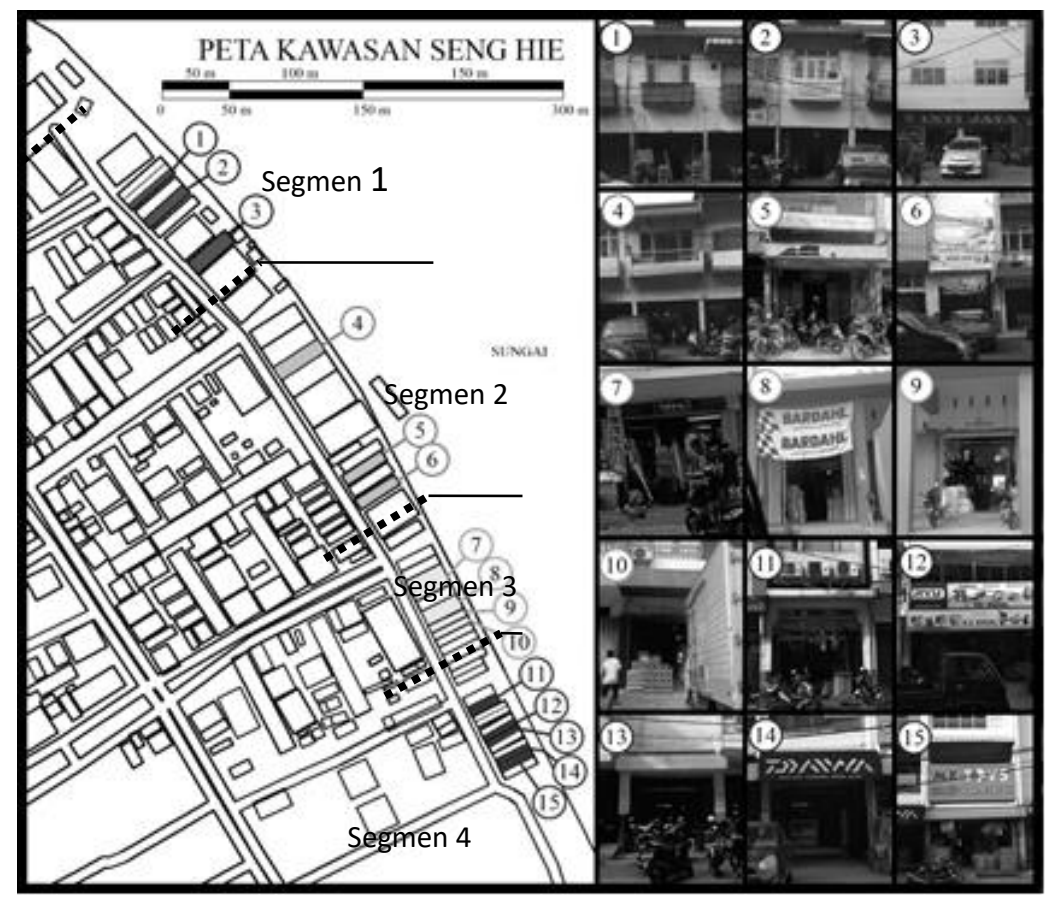

Gambar 1. Sebaran Sampel Penelitian di Desa Sungai Kakap Sumber: Tim Peneliti, 2019

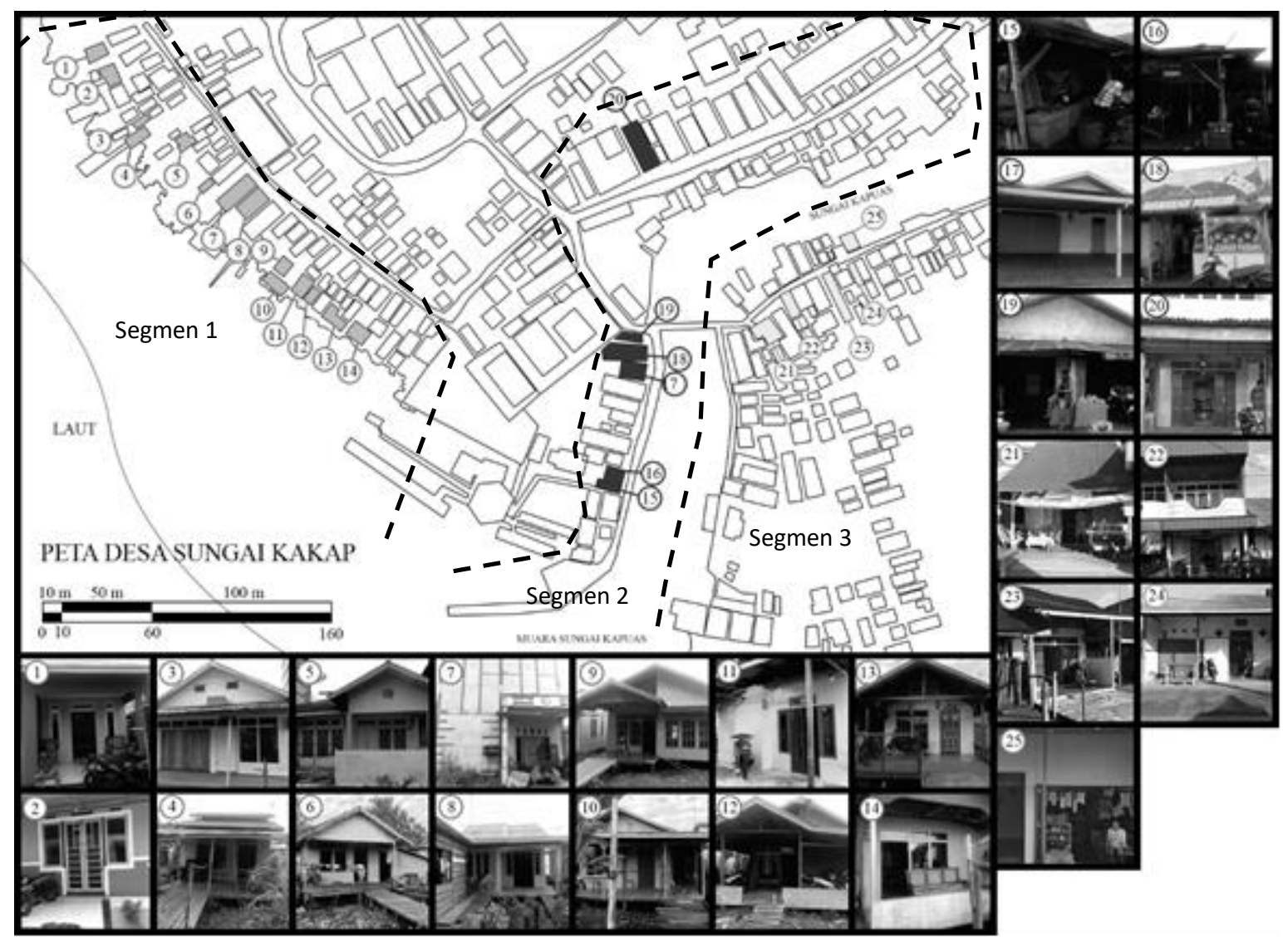

Gambar 2. Sebaran Sampel Penelitian di Kawasan Seng Hie Sumber: Tim Peneliti, 2019 
Tahap penelitian ini dibagi menjadi 5 tahapan. Tahap pertama adalah melakukan observasi dan survey lapangan. Survey lapangan terhadap elemen bangunan berupa lantai, dinding, plafond dan atap. Tahap kedua adalah menyusun variabel, populasi, dan sampel penelitian. Tahap ketiga adalah melakukan pengumpulan data sampel melalui observasi, pengambilan gambar foto, dan wawancara. Pengumpulana data dilakukan dengan observasi dan mengambil foto elemen bangunan berupa lantai, dinding, plafon dan atap, serta wawancara tentang bencana dan tindakan yang pernah terjadi. Tahap keempat adalah analisis data dengan mengidentifikasi adaptasi bangunan yang dilakukan masyarakat untuk merespon bencana dan adaptasi perilaku yang dilakukan masyarakat untuk merespon bencana. Tahap kelima adalah membuat kesimpulan tentang model adaptasi bencana yang dilakukan masyarakat di 2 lokasi penelitian.

Teknik pengumpulan data dilakukan secara kualitatif yaitu dengan teknik triangulasi (observasi, wawancara, serta studi dokumentasi) (Sugiyono, 2018). Observasi dilakukan dengan pengamatan perubahan dan adaptasi bentuk fisik yang dilakukan masyarakat. Wawancara secara terstruktur ditujukan kepada responden dengan pertanyaan terkait tindakan adaptasi bencana yang dilakukan masyarakat. Studi dokumentasi yang dilakukan adalah dengan melakukan pengambilan gambar bangunan dan lingkungan kawasan studi serta mencari data kondisi lingkungan dan kesehatan masyarakat sekitar dari instansi terkait.

Teknik analisis data dalam penelitian ini adalah deskriptif kualitatif. Teknik ini mengembangkan teori adaptasi bangunan dan adaptasi perilaku berdasarkan fakta data lapangan. Analisis data ini akan memberikan kesimpulan generalisasi tentang tindakan adaptasi dari sampel objek yang terpilih.

\section{Hasil dan Pembahasan}

\section{Identifikasi Tindakan Adaptasi Bangunan di Kawasan Seng Hie}

Berdasarkan hasil observasi dan wawancara, tim peneliti menemukan bahwa dari 15 objek masyarakat kawasan Seng Hie melakukan tindakan adaptasi yang seragam. Sebab mereka tidak merasa terancam oleh bencana banjir, sehingga tindakan adaptasi yang hampir seperti tidak melakukan apa-apa untuk menangani bencana tersebut. Menurut mereka banjir tahunan itu terjadi dalam waktu yang singkat (sekitar 1 jam dalam 1 tahun) dan dampak yang tidak berbahaya atau merugikan. Namun, hal menarik yang ditemukan disini adalah bangunan di kawasan ini dirancang dengan mempertimbangkan permasalahan banjir ini sebelum terbangun.

Tindakan adaptasi bangunan ruko di Kawasan Seng Hie adalah dengan melakukan renovasi. Mereka melakukan renovasi pada rumah mereka dengan alasan bangunan sudah rusak karena umur dan banjir. Selama merenovasi mereka merencanakan untuk meninggikan lantai agar air banjir tidak masuk lagi (Lihat Gambar 3). Bagian yang paling banyak direnovasi adalah lantai. Pada umumnya, ruko mereka dulu berlantai kayu diganti menjadi lantai beton. Adapun bagian dinding yang hanya beberapa rumah yang melakukan renovasi. Selain itu, alasan mereka melakukan renovasi juga untuk estetika atau memperindah rumah mereka. Dengan renovasi yang dilakukan oleh mereka, adaptasi bangunan ini tergolong dalam jenis adaptasi bangunan flexibility. Artinya, dengan bangunan dapat melakukan perubahan skala kecil yaitu perubahan ketinggian lantai yang dapat ditinggikan terus sesuai kebutuhan agar air tidak naik atau masuk ke dalam rumah. 


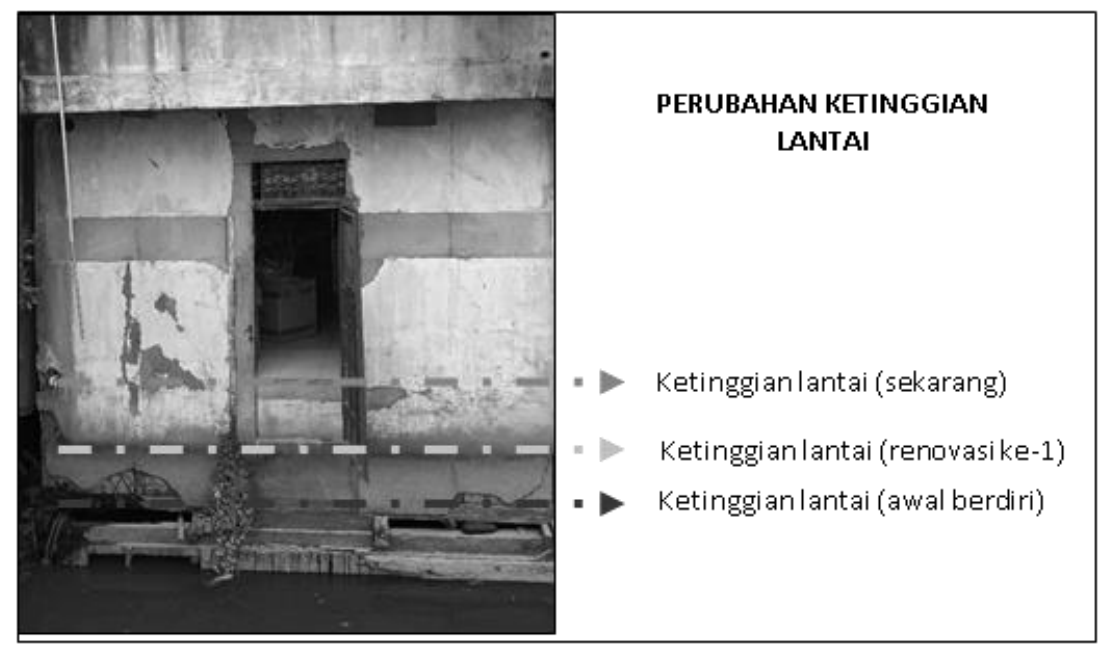

Gambar 3. Tampak Belakang Rumah Objek 11

Sumber: Tim Peneliti, 2019

Tindakan adaptasi perilaku yang dilakukan masyarakat kawasan Seng Hie pada saat banjir adalah menaikkan barang berharga, dan menunggu sampai air surut. Mereka tidak mengungsi ke tempat lain. Mereka tetap berada di rumah sampai air surut. Rumah mereka yang bertingkat 2 sampai 3 membuat mereka dapat tetap beraktivitas di dalam rumah. Banjir tahunan ini tidak membuat mereka meninggalkan kawasan ini sebab menurut mereka banjir ini tidak menjadi ancaman bagi mereka. Tindakan adaptasi perilaku ini berdasarkan teori tergolong ke dalam adaptasi dengan perbaikan (adaptation by adjustment), dimana masyarakat Kawasan Seng Hie melakukan modifikasi pada bangunan agar sesuai dengan kebutuhan.

\section{Identifikasi Tindakan Adaptasi Bangunan di Desa Sungai Kakap}

Berdasarkan hasil observasi dan wawancara, tim peneliti menemukan bahwa dari 25 objek penelitian terdapat tindakan adaptasi yang berbeda-beda. Ada 4 kelompok adaptasi yang dilakukan masyarakat Desa Sungai Kakap. Kelompok ini dibedakan berdasarkan tindakan adaptasi bangunan dan adaptasi perilaku yang mereka lakukan. Kelompok tersebut diuraikan dalam Tabel 1.

Tabel 1. Kelompok Adaptasi di Desa Sungai Kakap

\begin{tabular}{|c|c|c|c|c|c|}
\hline No & $\begin{array}{c}\text { Kelompok } \\
\text { Adaptasi }\end{array}$ & $\begin{array}{c}\text { Jumlah } \\
\text { Objek }\end{array}$ & $\begin{array}{l}\text { Nomor } \\
\text { Objek }\end{array}$ & $\begin{array}{l}\text { Tipe Adaptasi } \\
\text { Bangunan }\end{array}$ & $\begin{array}{l}\text { Tipe Adaptasi } \\
\text { Perilaku }\end{array}$ \\
\hline 1 & $\begin{array}{l}\text { Kelompok } \\
\text { Satu }\end{array}$ & 6 & $\begin{array}{c}3,6,15,16 \\
18, \text { dan } 21\end{array}$ & Generality & $\begin{array}{l}\text { Adaption by } \\
\text { withdrawal }\end{array}$ \\
\hline 2 & $\begin{array}{l}\text { Kelompok } \\
\text { Dua }\end{array}$ & 15 & $\begin{array}{c}1,2,4,5,7, \\
8,9,10,11, \\
12,13,14, \\
22,23, \text { dan } \\
24\end{array}$ & Flexibility & $\begin{array}{c}\text { Adaptation by } \\
\text { adjustment }\end{array}$ \\
\hline 3 & $\begin{array}{l}\text { Kelompok } \\
\text { Tiga }\end{array}$ & 3 & $\begin{array}{c}17,19, \text { dan } \\
25\end{array}$ & Generality & $\begin{array}{c}\text { Adaptation by } \\
\text { reaction }\end{array}$ \\
\hline 4 & $\begin{array}{c}\text { Kelompok } \\
\text { Empat }\end{array}$ & 1 & 20 & Elascity & $\begin{array}{c}\text { Adaptation by } \\
\text { adjustment }\end{array}$ \\
\hline
\end{tabular}

Sumber: Tim Peneliti, 2019 
Kelompok Satu adalah mereka yang sejauh ini tidak melakukan apa-apa pada bangunannya untuk menghadapi banjir. Rumah mereka memiliki lantai bermaterial kayu dan dinding ada yang dari kayu dan juga dari campuran kayu dan beton (Lihat Gambar 4). Pada saat banjir lantai rumah mereka terendam setinggi $5 \mathrm{~cm}$ sampai $10 \mathrm{~cm}$. Tindakan yang mereka lakukan saat banjir adalah menyelamatkan barang-barang yang dapat rusak oleh air. Sebagian dari mereka juga mengungsi ke tempat lain. Kelompok ini melakukan adaptasi bangunan jenis generality dan melakukan adaptasi perilaku dengan penarikan (adaptation by withdrawal) diri dari lingkungan mereka.

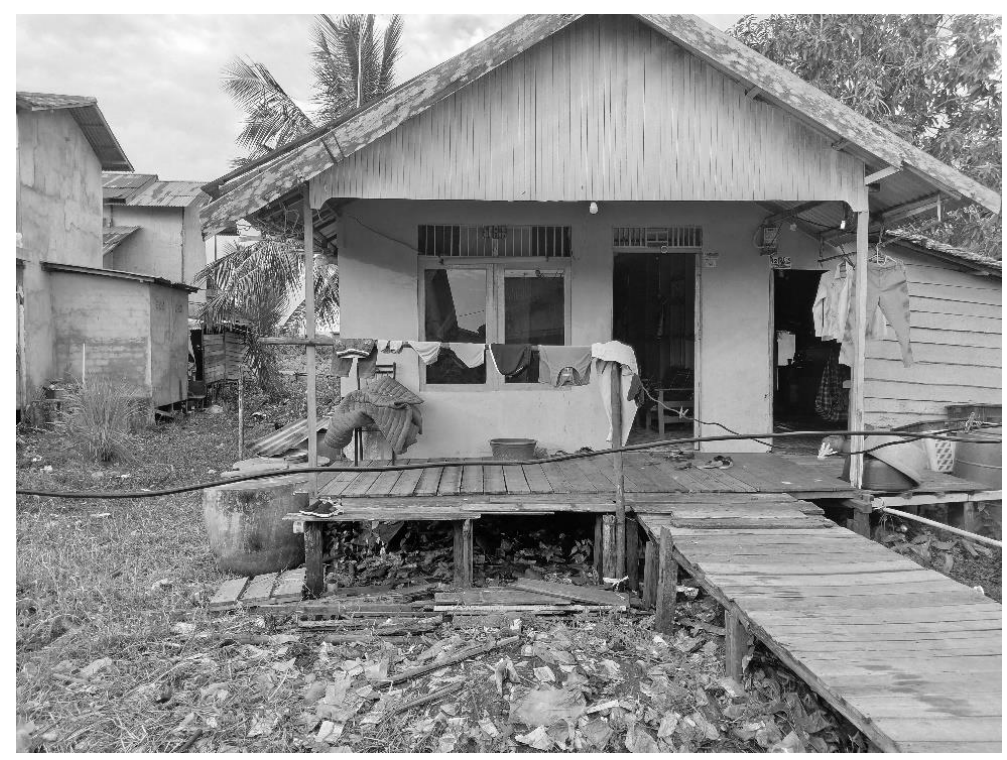

Gambar 4. Rumah di Desa Sungai Kakap - Objek ke-6 Sumber: Tim Peneliti, 2019

Kelompok dua adalah masyarakat yang melakukan renovasi lantai rumahnya menjadi beton. Bagian yang paling sering direnovasi adalah lantai rumah. Mereka mengganti lantai kayu menjadi lantai beton dan elevasi lantai menjadi lebih tinggi (Lihat Gambar 5). Mereka mengaku bahwa setelah meninggikan lantai, air banjir tidak masuk ke dalam rumah lagi. Dengan renovasi yang mereka lakukan, pada saat terjadi banjir, mereka dapat tetap melakukan aktivitas seperti biasanya. Jenis adaptasi bangunan yang dilakukan adalah adaptasi flexibility dan adaptasi perilaku yang dilakukan adalah adaptation by adjustment (melakukan perbaikan). 


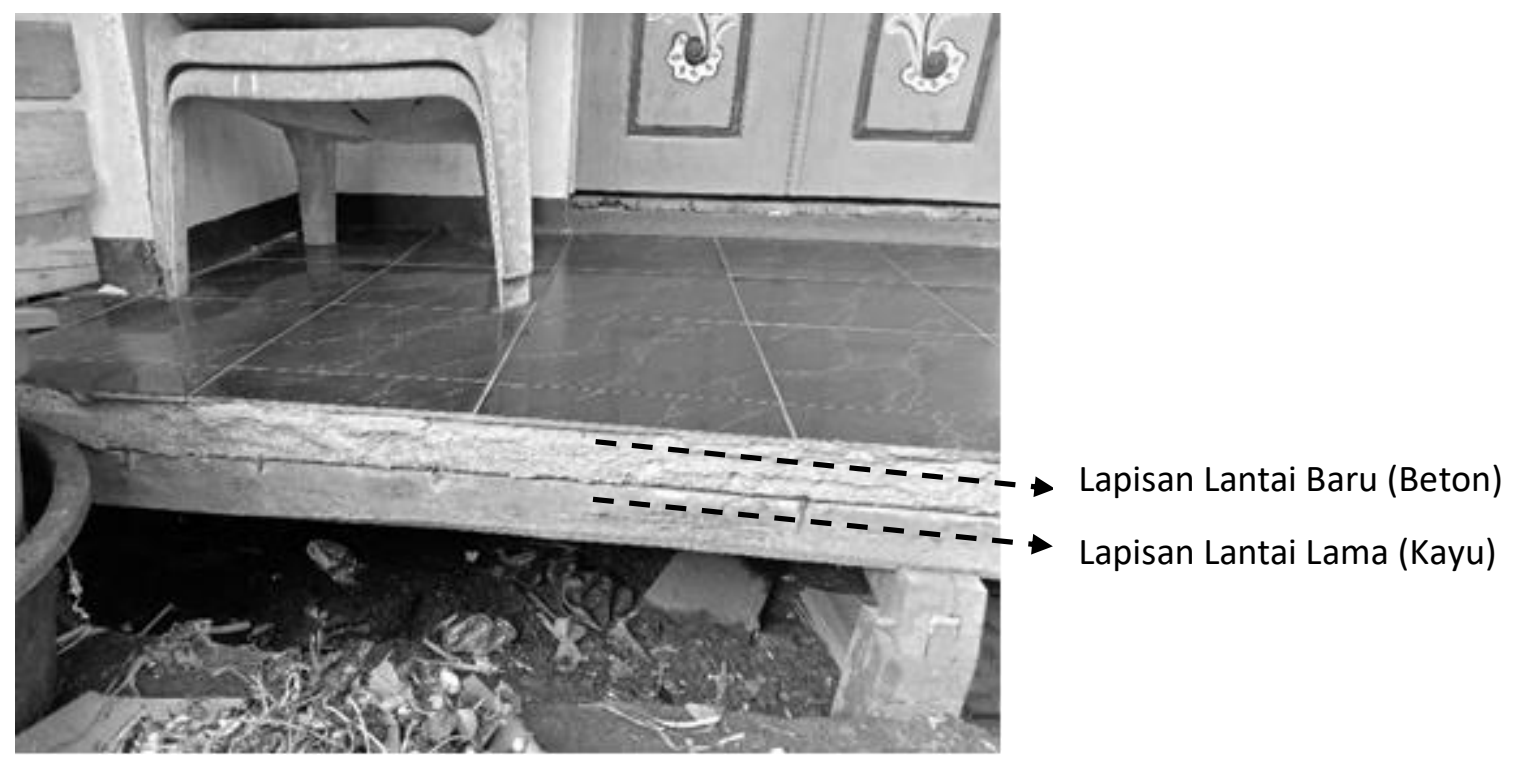

Gambar 5. Lantai yang Telah Ditinggikan - Objek 9

Sumber: Tim Peneliti, 2019

Kelompok tiga adalah masyarakat yang melakukan renovasi tetapi tidak menyelesaikan masalah banjir. Mereka melakukan perubahan pada lantai tetapi tidak mengganti material (tetap lantai kayu) dan juga tidak meninggikan elevasi lantai. Mereka tidak merasa terancam oleh bencana banjir tersebut. Pada saat bencana banjir terjadi mereka menyelamatkan barang berharga agar tidak terendam dan menunggu air surut. Kelompok ini memerlukan lantai kayu dengan alasan usaha (pekerjaan). Lantai kayu memudahkan mereka untuk mencuci ikan dan sayur di depan rumah. Jenis adaptasi bangunan yang dilakukan adalah adaptasi generality dan adaptasi perilaku yang dilakukan adalah adaptation by reaction (menyesuaikan tindakan) (Lihat Gambar 6).

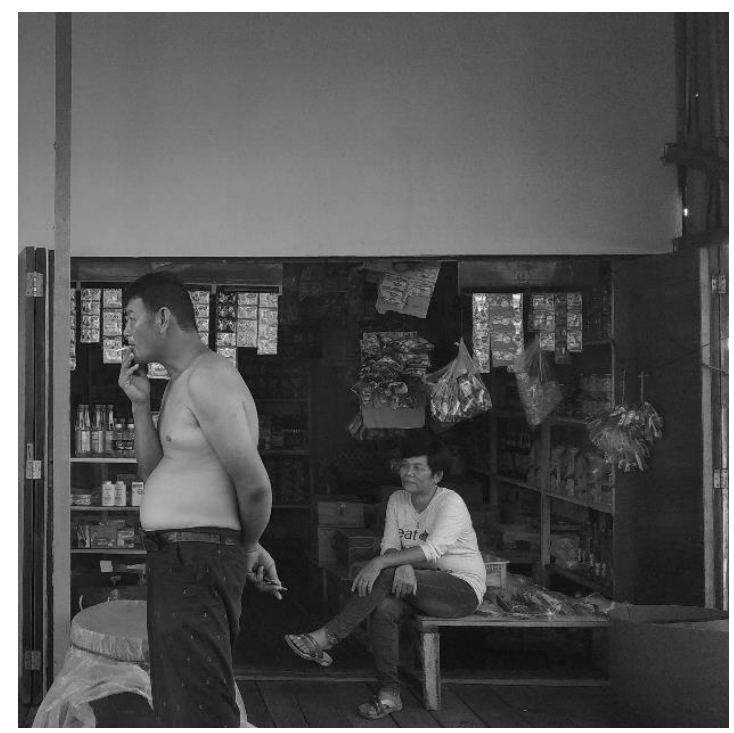

Gambar 6. Rumah Objek 25

Sumber: Tim Peneliti, 2019

Kelompok empat adalah masyarakat yang melakukan renovasi pada rumahnya tetapi ketinggian lantai mereka tetap dapat dimasuki oleh air banjir. Mereka memiliki solusi adaptasi 
bangunan yang fleksibel untuk menghadapi banjir yaitu dengan membuat penghalang air dari papan kayu agar air tidak masuk. Pagar kayu ini dilapisi dengan lem kapal agar tidak dilewati oleh air (Lihat Gambar 7). Jenis adaptasi bangunan yang dilakukan adalah adaptasi elasticity dan adaptasi perilaku yang dilakukan adalah adaptation by adjustment (melakukan perbaikan).

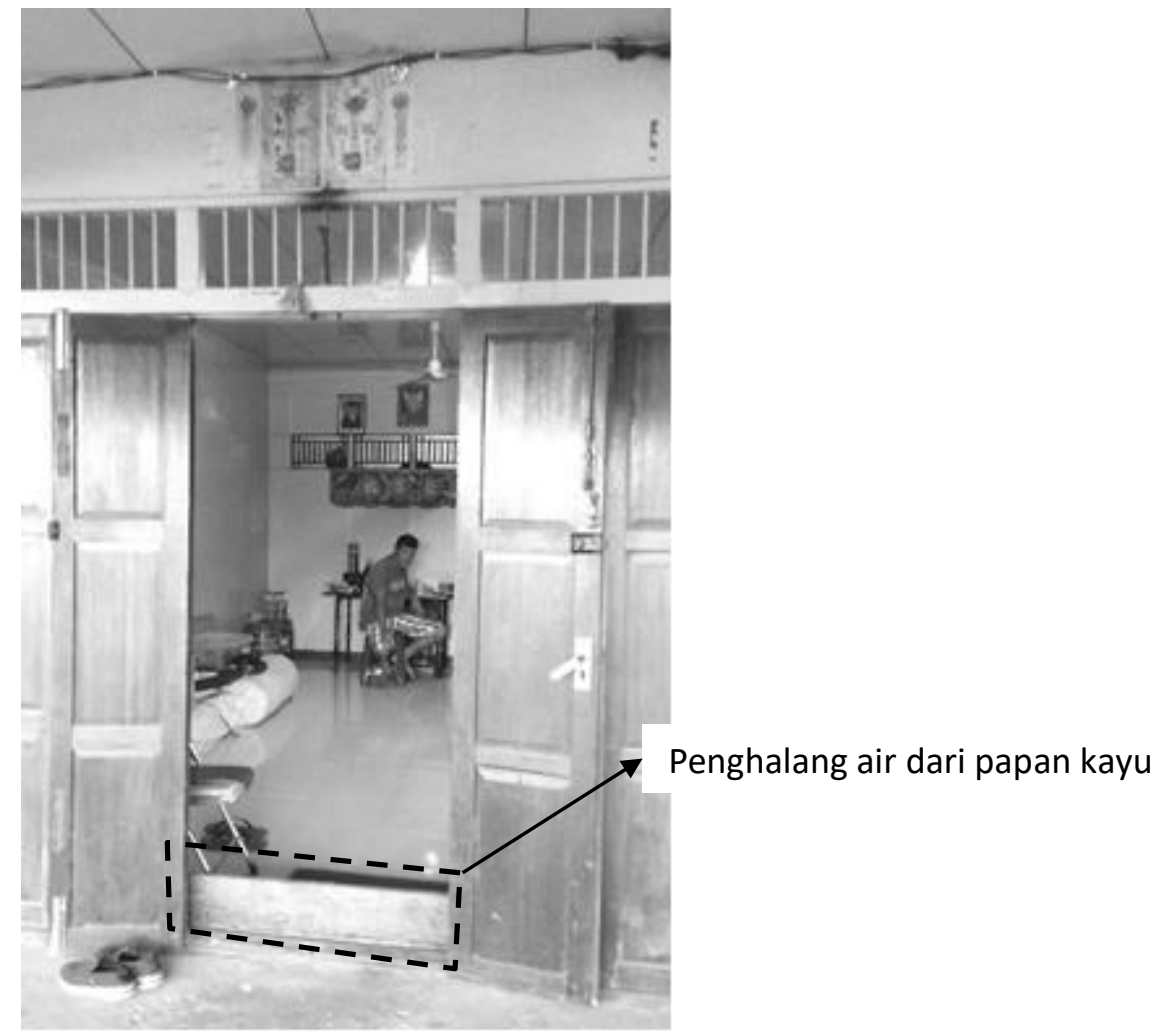

Gambar 7. Pagar Kayu - Objek ke-20

Sumber: Tim Peneliti, 2019

Pada bagian belakang rumah sudah disiapkan saluran pembuangan untuk mengeluarkan air banjir yang telah masuk (Lihat Gambar 8). Rumah objek ke 20, memiliki elevasi lantai yang sama (datar) dari depan sampai belakang rumah. Mereka mengatakan pemagaran hanya bisa dilakukan bila lantai rumah berbahan beton (tidak ditembusi oleh air). 


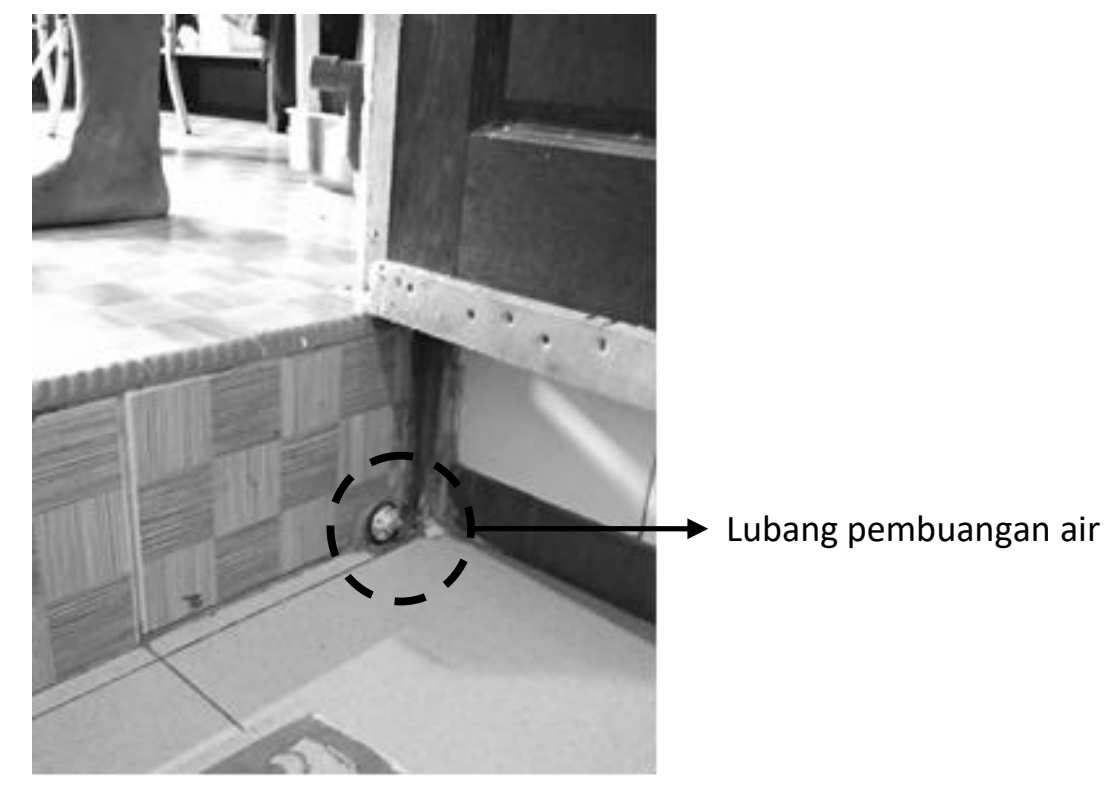

Gambar 8. Lubang Pembuangan Air Banjir - Objek 20

Sumber: Tim Peneliti, 2019

\section{Kesimpulan}

Berdasarkan hasil wawancara, dan observasi, dapat disimpulkan ada 5 jenis model adaptasi bencana yang ditemukan. Pengelompokkan model ini didasarkan pada kombinasi adaptasi bangunan dan perilaku, serta dari renovasi yang dilakukan. Bangunan-bangunan di Kawasan Seng Hie memiliki model adaptasi yang seragam sehingga hanya ditemukan 1 model adaptasi, sedangkan di Desa Sungai Kakap terdapat 4 jenis model adaptasi bencana. Model-model adaptasi tersebut dijabarkan dalam poin-poin berikut:

a. Model pertama adalah model adaptasi bencana masyarakat Kawasan Seng Hie. Renovasi yang dilakukan adalah renovasi lantai dari lantai kayu kemudian terus ditinggikan dengan ditambah beton menyesuaikan kenaikan permukaan air dari tahun ke tahun (Lihat Gambar 9). Kombinasi adaptasinya terdiri dari adaptasi bangunan jenis flexibility dan adaptasi perilaku jenis adaptation by adjustment.

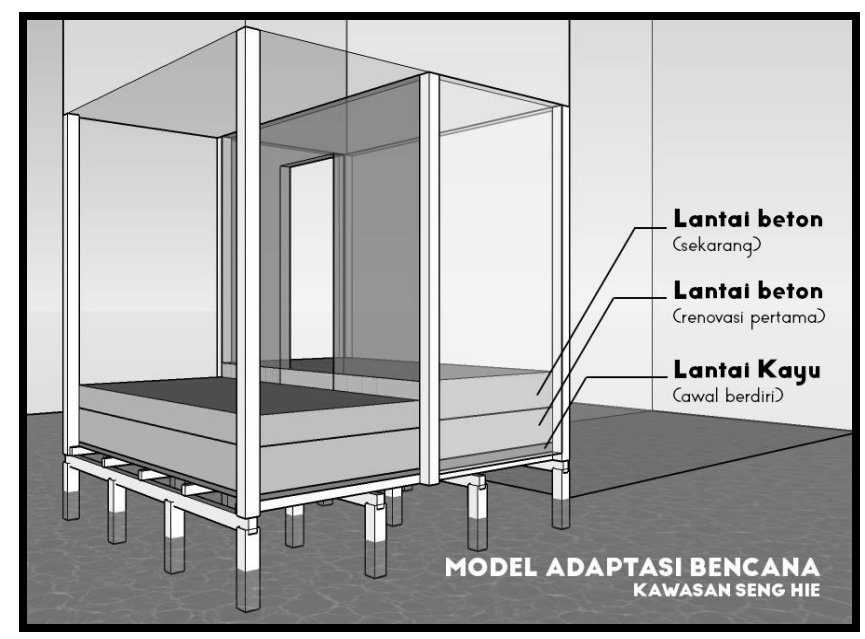

Gambar 9. Ilustrasi Model Adaptasi Kawasan Seng Hie Sumber: Tim Peneliti, 2019 
b. Model kedua adalah model bencana masyarakat Desa Sungai Kakap kelompok 1. Tidak ada renovasi yang dilakukan (Lihat Gambar 10). Kombinasi adaptasinya terdiri dari adaptasi bangunan jenis generality dan adaptasi perilaku jenis adaptation by withdrawal.

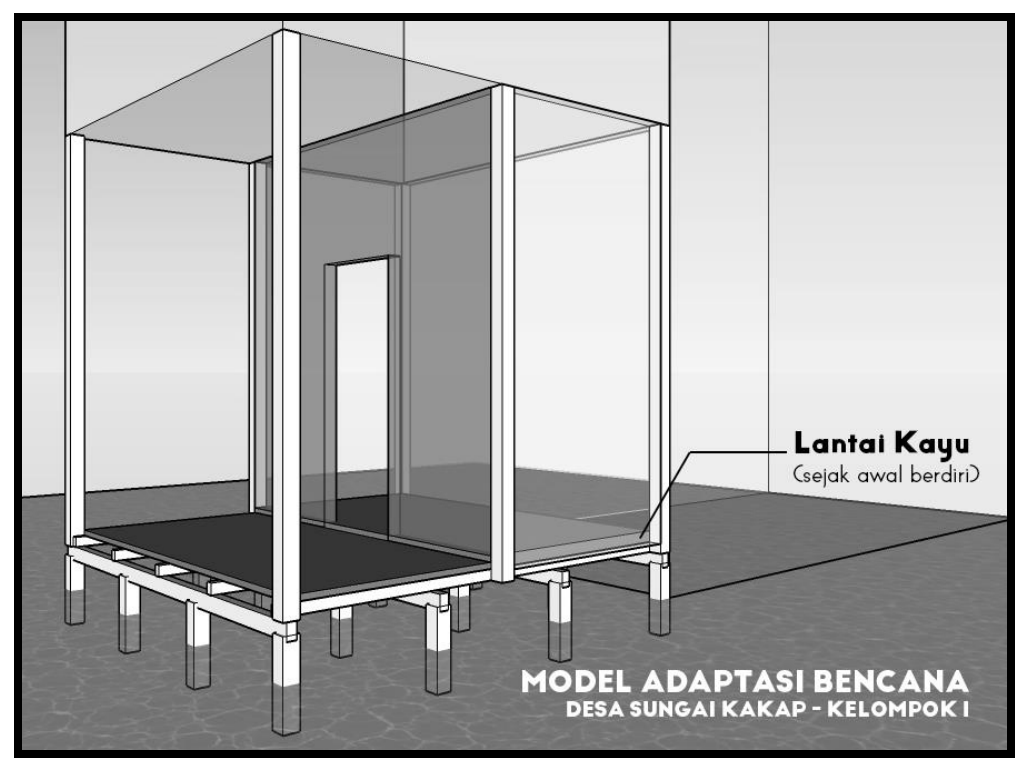

Gambar 10. Ilustrasi Model Adaptasi Desa Sungai Kakap - Kelompok 1 Sumber: Tim Peneliti, 2019

c. Model ketiga adalah adaptasi bencana masyarakat Desa Sungai Kakap kelompok 2. Renovasi yang dilakukan adalah renovasi lantai dari lantai kayu dapat terus ditinggikan dengan ditambah beton dan hanya dilakukan sekali saja (Lihat Gambar 11). Kombinasi adaptasi terdiri dari adaptasi bangunan jenis flexibility dan adaptasi perilaku jenis adaptation by adjustment.

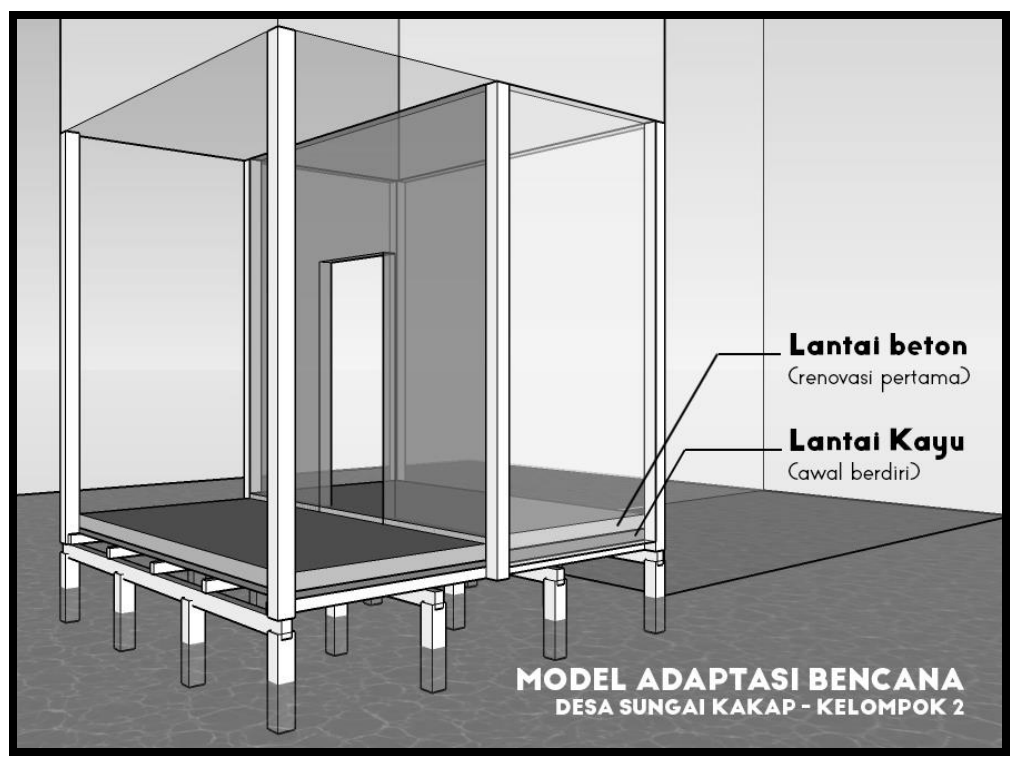

Gambar 11. Ilustrasi Model Adaptasi Desa Sungai Kakap - Kelompok 2

Sumber: Tim Peneliti, 2019 
d. Model keempat adalah model adaptasi bencana masyarakat Desa Sungai Kakap kelompok 3. Renovasi yang dilakukan adalah dengan renovasi lantai yang awalnya dari lantai kayu direnovasi kembali seperti pada keadaan semula yaitu lantai kayu (Lihat Gambar 12). Kombinasi adaptasi terdiri dari adaptasi bangunan jenis generality dan adaptasi perilaku jenis adaptation by reaction.

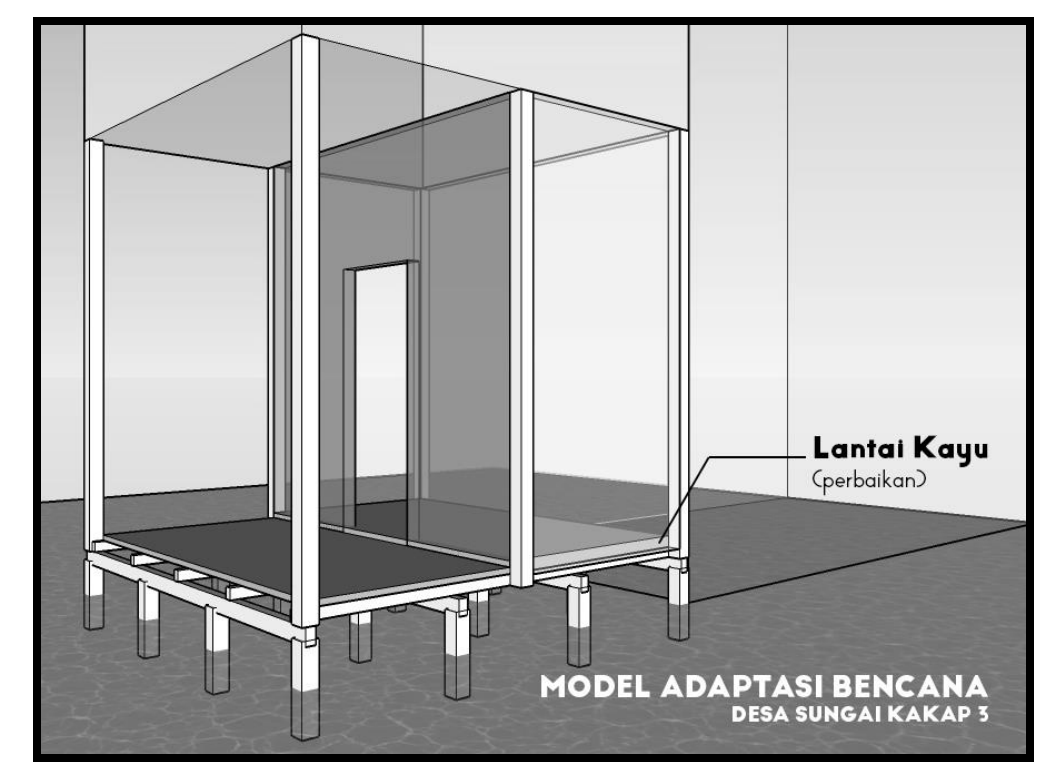

Gambar 12. Ilustrasi Model Adaptasi Desa Sungai Kakap - Kelompok 3

Sumber: Tim Peneliti, 2019

e. Model kelima adalah model adaptasi bencana masyarakat desa sungai kakap kelompok 4 . Renovasi yang dilakukan adalah renovasi lantai yang awalnya dari lantai kayu dilapis dengan bahan beton, kemudian pembatas papan kayu di pintu masuk, serta lubang saluran mengeluarkan air di belakang rumah (Lihat Gambar 13). Kombinasi adaptasi model ini terdiri dari adaptasi bangunan jenis elasticity dan dengan adaptasi perilaku jenis adaptation by adjustment. 


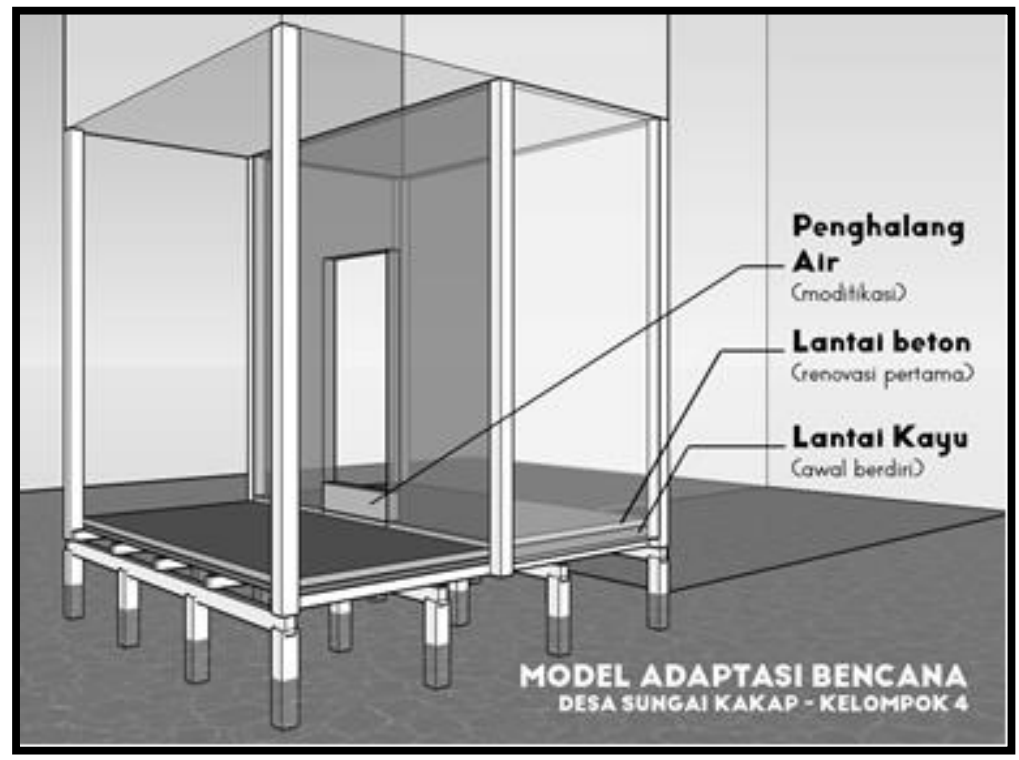

Gambar 13. Ilustrasi Model Adaptasi Desa Sungai Kakap - Kelompok 4 Sumber: Tim Peneliti, 2019

\section{Daftar Pustaka}

Breen, A., \& Rigby, D. (1994). Waterfronts: cities reclaim their edge. New York: McGraw-Hill Professional Publishing.

Cahyadi, A., Marfai, M. A., Mardiatno, D., \& Nucifera, F. (2017, 9). Pemodelan Spasial Bahaya Banjir Rob Berdasarkan Skenario Perubahan Iklim dan Dampaknya di Pesisir Pekalongan. Jurnal Bumi Lestari, 13, 244-256.

Carmichael, D. G., \& Taheriattar, R. (2018, 11). Valuing deliberate built-in flexibility in houses Exampled. International Journal of Strategic Property Management, 22, 479-488.

Ching, F. D., \& Adams, C. (2008). Ilustrasi Konstruksi Bangunan (3rd ed.). Jakarta: Erlangga.

Ching, F. D., \& Eckler, J. F. (2013). Introduction to Architecture. New Jersey: John Wiley \& Sons.

Country, U. B. (2018). King Tides Initiative 2018. Florida: Broward Country.

Depdiknas, P. B. (2008). Kamus Bahasa Indonesia. Jakarta: Pusat Bahasa.

EPA. (2011). King Tides - Climate Ready Estuaries. Washington DC: EPA.

Gultom, B. J. (2016). Identifikas dan Evaluasi Akses Publik dan Open Space di Kawasan Seng Hie Pontianak. Langkau Betang, III(1), 14-27.

Hermon, D. (2018, 9). Mitigasi Bencana Hidrometeorologi: Banjir, Longsor, Ekologi, Degradasi Lahan, Puting Beliung, Kekeringan. Padang: UNP Press.
Kostopoulou, S. (2013). On the Revitalized Waterfront: Creative Milieu for Creative Tourism. Sustainability, 5(11), 4578-4593.

Kurniawan, R., Najib Habibie, M., \& Permana, D. (2012, 12). Kajian Daerah Rawan Gelombang Tinggi di Perairan Indonesia (Study on High wave Prone Areas Over Indenesian Waters). Jurnal Meteorologi dan Geofisika, 13, 201-212.

Misavan, D. F., \& Gultom, B. J. (2014). Pengaruh Pembaruan Fasad Bangunan Terhadap Karakter Visual Kawasan, Studi Kasus : Jalan Tanjungpura Pontianak. Langkau Betang, I(2), $1-16$.

Sugiyono. (2018). Metode Penelitian Kombinasi (Mixed Methods). Bandung: Alfabeta.

Timur, U. P. (2013). Urban Waterfront Regenerations. Intech Open: Advances in Landscape Architecture, 1(1), 169-206.

Wardhana, W. A. (2010). Dampak pemanasan global (Vol. 190). Yogyakarta: Andi Offset.

Yusuf, M. A., Hayati, A., \& Faqih, M. (2018, 10). Concept of Female Dormitory Bedrooms Based on Students Preference and Adapatation. Journal of Architecture \& Environment, 17, 169-194. 